\title{
Developing nephrology services in low income countries: a case of Tanzania
}

\author{
Francis F. Furia ${ }^{1,2^{*}} \mathbb{D}$, Jacqueline Shoo ${ }^{1,2}$, Paschal J. Ruggajo ${ }^{1,2}$, Kajiru Kilonzo ${ }^{3}$, Gopal Basu ${ }^{4,5}$, Karen Yeates ${ }^{6}$, \\ Santosh Varughese ${ }^{7}$, Einar Svarstad ${ }^{8}$ and Onesmo Kisanga ${ }^{1,2}$
}

\begin{abstract}
Background: The burden of kidney diseases is reported to be higher in lower- and middle-income countries as compared to developed countries, and countries in sub-Saharan Africa are reported to be most affected. Health systems in most sub-Sahara African countries have limited capacity in the form of trained and skilled health care providers, diagnostic support, equipment and policies to provide nephrology services. Several initiatives have been implemented to support establishment of these services.
\end{abstract}

Methods: This is a situation analysis to examine the nephrology services in Tanzania. It was conducted by interviewing key personnel in institutions providing nephrology services aiming at describing available services and international collaborators supporting nephrology services.

Results: Tanzania is a low-income country in Sub-Saharan Africa with a population of more than 55 million that has seen remarkable improvement in the provision of nephrology services and these include increase in the number of nephrologists to 14 in 2018 from one in 2006, increase in number of dialysis units from one unit (0.03 unit per million) before 2007 to 28 units ( 0.5 units per million) in 2018 and improved diagnostic services with introduction of nephropathology services. Government of Tanzania has been providing kidney transplantation services by funding referral of donor and recipients abroad and has now introduced local transplantation services in two hospitals. There have been strong international collaborators who have supported nephrology services and establishment of nephrology training in Tanzania.

Conclusion: Tanzania has seen remarkable achievement in provision of nephrology services and provides an interesting model to be used in supporting nephrology services in low income countries.

Keywords: Nephrology in Tanzania, Nephrology training, Nephrology in sub-Saharan Africa

\section{Background}

Non-communicable diseases (NCD) are reported to contribute significantly to mortality and morbidity globally, with more than $70 \%$ of global mortality estimated to be attributable to NCD [1,2]. Tanzania, like many other sub-Saharan African (SSA) countries is faced with a growing burden of non-communicable diseases. The rising burden of NCD has put strain on the health system which historically was overwhelmed by managing communicable diseases [3]. Kidney diseases have contributed significantly to increased risk and burden of cardiovascular

\footnotetext{
* Correspondence: fredrick.francis78@gmail.com

${ }^{1}$ School of Medicine, Muhimbili University of Health Sciences (MUHAS), P. O. Box 65001, Dar es Salaam, Tanzania

${ }^{2}$ Renal Unit, Muhimbili National Hospital (MNH), Dar es Salaam, Tanzania Full list of author information is available at the end of the article
}

diseases as well as mortality in Tanzania and other low and middle-income countries (LMICs) [4].

There is global disparity in the availability of nephrology services with limited or non-existing services in many lower-income countries most of which are in subSaharan Africa. Resources needed for addressing the growing burden of chronic kidney disease (CKD) in this region are scarce; these include diagnostic and therapeutic equipment as well as the human resources and facilities for training them [5]. A few countries in subSaharan Africa have managed to establish some form of services; these services are of limited scope and not comprehensive enough to address the huge burden of CKD in the region [6].

C The Author(s). 2019 Open Access This article is distributed under the terms of the Creative Commons Attribution 4.0 International License (http://creativecommons.org/licenses/by/4.0/), which permits unrestricted use, distribution, and reproduction in any medium, provided you give appropriate credit to the original author(s) and the source, provide a link to the Creative Commons license, and indicate if changes were made. The Creative Commons Public Domain Dedication waiver (http://creativecommons.org/publicdomain/zero/1.0/) applies to the data made available in this article, unless otherwise stated. 
Global efforts have seen the establishment and improvement of nephrology services in many lower income countries, and the International Society of Nephrology (ISN) has played a significant role in training nephrologists $[7,8]$. Despite these efforts there is still a huge gap in the availability and access to these services in most of sub-Saharan Africa [9].

Tanzania located in East Africa and with a population of over 55 million people is divided administratively into 30 regions and 7 zones. Health system in Tanzania is organized into clearly defined referral system linking primary health care facilities to the national hospital. Dispensary which serve an estimated population of 10,000 people is the lowest level and it feeds patients into health centres which has capacity of emergency surgeries. Several health centres are supported by the district hospital. Each region has one regional hospital and 4-6 district hospitals, regional hospitals refer patients to zonal consultant hospitals and the national hospital. There are four zonal consultant hospitals all of which offer specialized services. There are several private hospitals most of which are in big cities which also provide specialized services.

Tanzania has made significant improvement in the provision of services for non-communicable diseases in the past two decades. Among the NCD which has high burden is diabetes mellitus, in 2006 about 400,000 people were estimated to be diabetic therefore Tanzania Diabetes Association and ministry of health established diabetic clinics in many regional hospitals [10]. This progress has been made possible through collaborative support from several international institutions and organizations. This article is aimed at highlighting the current status of renal diseases and nephrology services in Tanzania. The strategies, key achievements and current challenges facing the national health system in provision of nephrology services are discussed. The importance of international support and collaborative initiatives are outlined, and the Tanzanian experience could potentially serve as a model for implementing modern nephrology services in resource limited settings.

\section{Burden of kidney diseases in Tanzania}

There is paucity of data on the burden of kidney diseases in Tanzania as is the case in many resource-limited countries. Available administrative and research data from hospital and community-based facilities indicate a high prevalence of kidney diseases. Stanifer et al. reported a CKD prevalence of $7 \%$ in the community setting in Northern Tanzania, with significantly higher prevalence in urban setting (15\%) as compared to rural setting (2\%) [11]. Ploth et al. documented a CKD prevalence of $12.4 \%$ while that of hypertension and diabetes were 19.9 and $14.8 \%$ respectively in rural Eastern
Tanzania, advanced CKD was noted to be higher among young people aged $18-36$ years [12].

Hospital based reports have also documented a high burden of kidney diseases. Janmohamed et al. reported a CKD prevalence of $83.7 \%$ among 397 diabetic patients attending a diabetic clinic, out of which $24.3 \%$ had eGFR of less than $60 \mathrm{ml} / \mathrm{min}$ from a study conducted at Bugando Medical Centre, a consultant zonal hospital in North-western Tanzania [13]. Another study from the same hospital reported renal dysfunction in $27.5 \%$ out of 637 adult patients admitted to the medical wards between October 2013 and March 2014 [14]. .A study conducted at the emergency medical department at Muhimbili National Hospital (MNH) between September 2017 and February 2018 reported renal failure in $8.8 \%$ out of 3013 screened patients, out of which 71 and 195 had acute kidney injury (AKI) and CKD respectively and 146 had indications for dialysis [15].

Human Immunodeficiency virus (HIV) infection, whose burden is high in sub-Saharan Africa, with a prevalence of $5 \%$ in Tanzania, is an important risk factor for kidney diseases in Tanzania. Msango et al. reported a prevalence of severe renal dysfunction (eGFR 30-59) of $24.5 \%$ out of 355 patients starting anti-retroviral therapy [16].

Kayange et al. documented a prevalence of kidney dysfunction (eGFR $<60 \mathrm{ml} / \mathrm{min}$ ) of 7.4 and $4.9 \%$ among HIV infected and un-infected children respectively, in a study conducted among admitted children at Bugando Medical Centre [17]. Fredrick et al. also reported a prevalence of severe renal dysfunction (eGFR $30-59 \mathrm{ml} / \mathrm{min}$ ) of $5.8 \%$ in a study conducted among HIV infected children attending clinic at Muhimbili National Hospital [18].

\section{Methodology}

This situation analysis undertaken to determine provision of nephrology services in Tanzania, which was approved by MUHAS institutional Review Committee, was carried out by interviewing key personnel in the facilities providing nephrology services in Tanzania. No individual information was sought during interviews therefore a waiver of consent was also granted by MUHAS IRB. Interviews were carried out through phone calls using a checklist which collected information about number of dialysis patients, number of haemodialysis machines in each unit, international collaborators and support provided by each international collaborator. Information about individual nephrologist/nephropathologist training was obtained from Nephrology Society of Tanzania. Information about kidney transplantation was obtained from Muhimbili National Hospital and Benjamin Mkapa Hospital which are currently offering local kidney transplantation services. Muhimbili National Hospital which coordinated overseas kidney transplantation provided information transplant services obtained out of Tanzania. 


\section{Results}

\section{Nephrology services}

Several services are offered for kidney diseases in Tanzania, and there has been a rapid increase in the number of facilities offering services for treatment of patients with end-stage kidney disease (ESKD). These services include haemodialysis, peritoneal dialysis and kidney transplantation. Importantly, renal clinics offering diagnostic services have been established in four zonal consultant hospitals which serve and average of 4-8 million population for each zone. Nephrologists and other clinicians provide services in renal clinics. Diagnostic supports for nephrology services to guide management of patients have been established including nephropathology [19].

\section{Haemodialysis}

Table 1 describes the location, number of dialysis machines and patients on maintenance haemodialysis in Tanzania as of 31st December 2018. There are 28 haemodialysis centres ( 0.5 units/million), some of these are in hospitals while others are stand-alone dialysis centres equipped with medical laboratory, procedures and consultations rooms. Most of the dialysis centres $75 \%(21 / 28)$ are privately owned and located in large cities in seven regions $(23.3 \%)$ out of all 30 regions in Tanzania. Fifteen $(53.6 \%)$ out of all dialysis units are in Dar es Salaam city. Both acute and maintenance haemodialysis are offered in most of the dialysis centres, patients with AKI are referred to stand alone dialysis units from hospitals not offering dialysis services [20].

\section{Peritoneal dialysis}

Acute peritoneal dialysis (PD) has been offered in Tanzania since 2009. This program was implemented at Kilimanjaro Christian Medical Centre (KCMC) and initially established and supported by the Sustainable Kidney Care Foundation (SKCF) (New York, USA) in partnership with the International Paediatric Nephrology Association (IPNA) and the ISN. After the program was established, the Saving Young Lives (SYL) program supported by ISN was introduced and continued to support the program at KCMC through support for training of health providers to provide acute PD. This program began with capacity building among doctors and nurses who were trained in Curitiba, Brazil. Initial supplies of catheters and PD fluids were provided through the SKCF [21-23]. Bugando Medical Centre is another centre in Tanzania, which has received support from SYL program for the establishment of acute PD services. At Muhimbili National Hospital, PD was introduced in 2012, and has been offered largely for children with acute kidney injury [24], and recently Agha Khan
Hospital in Dar es Salaam has introduced acute peritoneal dialysis for children with AKI.

\section{Kidney transplantation}

Kidney transplantation services were initiated for Tanzanians since the 80's. Initially end-stage kidney disease patients and their donors had to travel overseas for services. The first batch of patients who received kidney transplantation services were sent to St Thomas Hospital in United Kingdom [25]. Thereafter, patients were being sent to several hospitals in India, and a small number were sent to other countries including Kenya. A total of 250 patients had received kidney transplantation surgery overseas (mostly in India) with government funding of transplant programs which covered air travel and living expenses for donors and recipients. These patients and their donors received pre-transplantation work up at Muhimbili National Hospital (MNH) which included extensive evaluation of both donors and recipients prior to referral. Only living related donors whose relationship had been verified by DNA profiling could donate under this program, in order to curtail possibility of commercial unrelated donor kidney transplantation. After surgery, the pair would stay near the transplant centre for 3-6 months for initial post-transplantation care and then continue with follow up care at MNH.

In November 2017 Tanzania started offering kidney transplantation services locally. These have been introduced in two hospitals, MNH and Benjamin Mkapa Hospital (BMH) in Dodoma, the country's capital city. These services have been made possible by collaborating with hospitals from India and Japan for $\mathrm{MNH}$ and $\mathrm{BMH}$ respectively. Transplant surgeons, nephrologists, anaesthesiologists and nurses from India and Japan paired with local teams and carried out transplant surgeries and provided immediate post-transplant surgery care in this program. With ongoing capacity building that seeks to improve local capacity, the dependence on the visiting team continues to decline. A total of 28 patients have undergone transplantation since November 2017, out of which 24 were performed at $\mathrm{MNH}$ and 4 at $\mathrm{BMH}$. Currently, the national transplant program only includes living related donor kidney transplants.

\section{Kidney biopsies}

Parallel with development in renal replacement therapies described above, the nephrology trainees received training in doing kidney biopsy in Haukeland University Hospital, Norway and Christian Medical College, Vellore, India. The 1st kidney biopsy (in modern era) was conducted in 2012 at Muhimbili National Hospital and since then more than 100 renal biopsies including renal graft biopsies have been performed using modern real time ultrasound-guided techniques. The biopsies taken 
Table 1 Distribution of dialysis units in Tanzania

\begin{tabular}{|c|c|c|c|c|}
\hline $\begin{array}{l}\text { Name of Region } \\
\text { (Estimated population) }\end{array}$ & Name of Dialysis unit & $\begin{array}{l}\text { Number of } \\
\text { Haemodialysis } \\
\text { machines }\end{array}$ & $\begin{array}{l}\text { Number of } \\
\text { CRRT }^{\mathrm{e}} \text { machines }\end{array}$ & $\begin{array}{l}\text { Number of patients } \\
\text { on dialysis }\end{array}$ \\
\hline \multirow{15}{*}{$\begin{array}{l}\text { Dar es Salaam } \\
(4,364,541 \text { million })\end{array}$} & Muhimbili National Hospital ${ }^{a}$ & 42 & 1 & 227 \\
\hline & Muhimbili National Hospital- Mloganzilaa & 12 & & 29 \\
\hline & Agha Khan Hospital $^{\text {b }}$ & 8 & & 21 \\
\hline & Emilio Mzena Hospital $^{a}$ & 6 & & 8 \\
\hline & TMJ Hospital $^{c}$ & 7 & & 40 \\
\hline & TMJ polyclinic ${ }^{c}$ & 5 & & 3 \\
\hline & Regency Medical Centre ${ }^{c}$ & 22 & & 120 \\
\hline & Al-Shifaa Clinic ${ }^{c}$ & 8 & & 17 \\
\hline & Hindu Mandal Hospital (Dar es Salaam) ${ }^{\mathrm{b}}$ & 8 & & 35 \\
\hline & Hindu Mandal (Kunduchi) ${ }^{b}$ & 10 & & 9 \\
\hline & Kairuki Hospital $^{c}$ & 7 & 1 & 27 \\
\hline & Access Health Centre ${ }^{c}$ & 16 & & 84 \\
\hline & Sali International Hospital ${ }^{c}$ & 1 & & $\mathrm{NO}^{\mathrm{d}}$ \\
\hline & Apollo polyclinic ${ }^{c}$ & 4 & & $\mathrm{NO}^{\mathrm{d}}$ \\
\hline & $\mathrm{CCBRT}^{\mathrm{b}}$ & 8 & & $\mathrm{NO}^{\mathrm{d}}$ \\
\hline \multirow{2}{*}{$\begin{array}{l}\text { Arusha } \\
(1,694,310 \text { million) }\end{array}$} & Arusha Lutheran Medical centre ${ }^{b}$ & 6 & & 33 \\
\hline & NSK Hospitals ${ }^{c}$ & 13 & & 51 \\
\hline $\begin{array}{l}\text { Kilimanjaro } \\
(1,640,087 \text { million })\end{array}$ & Kilimanjaro Christian Medical Centre ${ }^{\mathrm{b}}$ & 5 & & 31 \\
\hline \multirow{2}{*}{$\begin{array}{l}\text { Dodoma } \\
(2,083,588 \text { million })\end{array}$} & University of Dodoma Health centre ${ }^{a}$ & 10 & & 21 \\
\hline & Benjamin Mkapa Hospital ${ }^{a}$ & 10 & 1 & 26 \\
\hline \multirow{2}{*}{$\begin{array}{l}\text { Mbeya } \\
(2,707,410 \text { million })\end{array}$} & Mbeya Referral Hospital ${ }^{a}$ & 5 & & 20 \\
\hline & Afya Check ${ }^{c}$ & 4 & & 7 \\
\hline \multirow{4}{*}{$\begin{array}{l}\text { Mwanza } \\
(2,772,509 \text { million })\end{array}$} & Bugando Medical centre $^{\mathrm{b}}$ & 10 & & 60 \\
\hline & Access Medical Centre ${ }^{c}$ & 8 & & 4 \\
\hline & Bio Health Centre ${ }^{c}$ & 5 & & 10 \\
\hline & Hindu Mandal ${ }^{b}$ & 10 & & NO \\
\hline \multirow{2}{*}{$\begin{array}{l}\text { Zanzibar } \\
(1,303,569 \text { million })\end{array}$} & Mnazimmoja Hospital $^{a}$ & 6 & & 34 \\
\hline & Global Hospital $^{c}$ & 3 & & 16 \\
\hline TOTAL & & 259 & 3 & 933 \\
\hline
\end{tabular}

${ }^{\mathrm{a}}$ Public institution; ${ }^{\mathrm{b}}$ Private not for profit including faith-based institutions; ${ }^{\mathrm{C}}$ Private institution

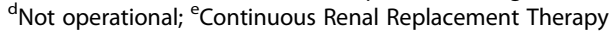

have aided in determining the underlying diagnoses and have guided both therapy and prognosis. The Haukeland University Hospital has sustained the kidney biopsybased nephrology practice in Tanzania by promoting hands-on-ultrasound-guided kidney biopsying through training as well as donating the starter-up gear (GE Logic 7 Ultrasound Machine, 2 Spring Loaded Magnum Bard Biopsy Guns and several kidney biopsy needles among others). The training of a Tanzanian nephropathologist in Norway, under the ISN Fellowship, on interpretation of both native kidney biopsies and allograft histopathology has added value to service development in the region. Regency Medical Centre is another hospital offering renal biopsy services in Tanzania.

\section{Human resources}

The number of nephrologists has increased in the past decade in Tanzania, from one in 2006 to 14 nephrologists in 2018. Nephrologists in Tanzania have been trained through a foreign government supported program to train local nephrologists introduced in 2007 at Muhimbili University of Health and Allied Sciences (MUHAS) as well as through the ISN fellowship program [26]. Ten nephrologists have been trained in the 
locally established training program at MUHAS and two of these nephrologists were through local partnerships with African countries including Ethiopia and Uganda.

The MUHAS Nephrology training program was initially offered in collaboration with University of Bergen in Norway and Christian Medical College in Vellore, Tamil Nadu- India. Candidates were initially trained in all three institutions and received their qualifications from MUHAS. Currently there are six nephrology trainees, three are training at MUHAS and three are under the ISN fellowship program with two in South Africa and one in India. Nephrology training at MUHAS is a 2 years program admitting physicians with training in internal medicine or general paediatrics, the program is housed in the department of Internal Medicine under School of Medicine.

MUHAS has been offering pathology training program at postgraduate level, this program had limited exposure in nephropathology until recently following introduction of nephropathology at Muhimbili National Hospital after successful completion of ISN fellowship in nephropathology by one pathologist from Tanzania. Some of pathology trainees at MUHAS, including the ISN fellow in nephropathology, have been participating in ISN-ANIO CNC online courses which have equipped them with a strong foundation and interest in nephropathology [27].

Nurses have largely provided haemodialysis care for ESKD patients in Tanzania. Training has occurred through programs where nurses receive short-term training (2-3 months) overseas; with most going to
India and some to Pakistan. Currently dialysis nurses are receiving training for few weeks to months in wellestablished dialysis units (mainly at the Muhimbili National Hospital). In a few centres, qualified dialysis technicians who are foreign nationals provide haemodialysis services.

In order to address the shortage of renal nurses, Muhimbili University of Health and Allied Sciences is in the final process of establishing post-graduate training in renal nursing (Master of Science in Renal nursing). This program will have four semesters for a duration of 2 years and will enrol nurses with a bachelor's degree. Table 2 shows the numbers and the countries in which nephrologists and nephropathologist have received training.

\section{Advocacy for nephrology}

Several advocacy campaigns for kidney health have been carried out in Tanzania largely under coordination with the Nephrology Society of Tanzania (NESOT). NESOT was established in 2012 and was then affiliated with the International Society of Nephrology in 2013 [26, 28]. Nephrologists in Tanzania have worked closely with Ministry of Health and other stakeholders in commemorating World Kidney Day annually with awareness raising and advocacy activities among the general population including screening for kidney health as well as diabetes and hypertension. Scientific conferences are conducted annually to provide a platform for continuous nephrology education and training for doctors, nurses and other stakeholders.

Table 2 Institutions and countries in which existing Tanzanian nephrologists and nephropathologist were trained

\begin{tabular}{|c|c|c|c|c|}
\hline $\begin{array}{l}\text { Country of } \\
\text { training }\end{array}$ & $\begin{array}{l}\text { Number of } \\
\text { trained doctors }\end{array}$ & Discipline & Training institution & Qualification \\
\hline \multirow[t]{2}{*}{ Tanzania } & $5^{a}$ & Nephrology & $\begin{array}{l}\text { MUHAS, UiB (Norway), Haukeland University Hospital (Norway), } \\
\text { Christian Medical College, Vellore (India) }\end{array}$ & MSc Nephrology \\
\hline & 5 & Nephrology & $\begin{array}{l}\text { MUHAS (with external rotation at the Christian Medical College, } \\
\text { Vellore, India) }\end{array}$ & MSc Nephrology \\
\hline India & 1 & Nephrology & Madras Medical Mission, Chennai -India & ISN Fellowship \\
\hline \multirow[t]{4}{*}{$\begin{array}{l}\text { South } \\
\text { Africa }\end{array}$} & 1 & Nephrology & UCT, Groote Schuur Hospital, Cape Town -South Africa & $\begin{array}{l}\text { Mphil Nephrology (UCT) } \\
\text { ISN Fellowship, Fellowship of } \\
\text { College of Medicine of South Africa }\end{array}$ \\
\hline & 1 & Nephrology & $\begin{array}{l}\text { Witwatersrand University, Chris Hani Baragwaneth Hospital, } \\
\text { Johannesburg, South Africa }\end{array}$ & $\begin{array}{l}\text { ISN Fellowship, Fellowship of } \\
\text { College of Medicine of South Africa }\end{array}$ \\
\hline & 1 & Nephrology & Stellenbosch University/ Tygerberg Hospital, South Africa & $\begin{array}{l}\text { ISN Fellowship, Fellowship of } \\
\text { College of Medicine of South Africa }\end{array}$ \\
\hline & $1^{\mathrm{b}}$ & $\begin{array}{l}\text { Paediatric } \\
\text { nephrology }\end{array}$ & $\begin{array}{l}\text { University of Cape Town, Red Cross Children Hospital, South } \\
\text { Africa }\end{array}$ & $\begin{array}{l}\text { ISN/IPNA Fellowship, Post-graduate } \\
\text { diploma, University of Cape Town }\end{array}$ \\
\hline Russia $^{c}$ & 2 & Nephrology & Nizhny Novgorod State Medical University, Russia & MMed Nephrology \\
\hline Norway & 1 & Nephropathology & University of Bergen/Haukeland University Hospital, Norway & ISN Fellowship \\
\hline
\end{tabular}

UiB University of Bergen, UCT University of Cape Town

${ }^{a}$ Two of the five nephrologists are from Ethiopia and Uganda

${ }^{b}$ MUHAS trained nephrologist

'Government supported training 
NESOT which has five zonal chapters in Tanzania; Eastern, Central, Lake and Southern, has provided important platform for engaging the government, health facilities, individual clinicians and other stakeholders in advancing nephrology services and improving access to this Tanzania. Increased awareness increased the number of doctors enrolling for local and international nephrology training programs. Networking among stakeholders has been fostered through various activities organized by NESOT including conferences and workshops.

\section{Collaborating partners for nephrology services in Tanzania}

Several international institutions have supported development of nephrology in Tanzania for the last decades. These supports have benefited several hospitals and medical schools with significant impact on establishing and advancing services for Tanzania. Table 3 below describes various international collaborations with Tanzanian institutions to support growth and sustainability of nephrology services.

\section{Discussion}

Nephrology services have seen dramatic changes in the past two decades in Tanzania. This is attributed to political will, government support, commitment of health care providers for training and increase in the awareness about the burden of kidney diseases, as well as active clinical research. Strong public-private partnership has promoted establishment of privately-owned dialysis units and this has strengthened provision of renal replacement therapy. International support and collaborations have played key roles in supporting capacity building, particularly in the training of health care providers and donation of equipment, which made introduction of new services possible. Nephrology training program in Tanzania is one of the remarkable achievements through which $57.1 \%(8 / 14)$ of all nephrologists in Tanzania have been trained, and the strong relationship between clinical and academic training has been of great importance [26].

Tanzania has witnessed a dramatic growth in number of dialysis units in the last decade, increasing from just one unit to 27 units in 2018 [25]. All dialysis units in Tanzania are located in 7 big cities in Tanzania, with majority of capacity in Dar es Salaam which accounts for about $10 \%$ of the Tanzanian population. There is limited access to regional dialysis services in the rest of the country as reported by Meremo et al. and Katunzi et al. in recent studies [20,29].

The other important challenge of dialysis services is the high cost of provision of haemodialysis, which has been estimated to be more than USD 27,400 per year per patient at Muhimbili National Hospital [30]. The price for each dialysis session in Tanzania ranges from USD 120-150. Funding for dialysis in Tanzania is through National Health Insurance Fund (NHIF), initially established to cover public servants and now also enrolling members from private sector. NHIF membership is $7.1 \%$ of Tanzania population and provides full reimbursement for dialysis services for its members [31]. Tanzanians who are not covered by NHIF must pay out of pocket for dialysis services, implying that only members of this fund have guaranteed access to dialysis and other nephrology services [28, 29]. As the dialysis activity is expected to rise substantially soon reducing costs of dialysis is of paramount importance. The professional commitment of Tanzanian nephrologists and NESOT aiming at fulfilling the goals of the ISN to reduce preventable deaths from acute kidney injury in low-income countries also highlights the needs of reducing costs and implementing a nationwide peritoneal dialysis program [32].

Kidney transplantation services were initially provided overseas making Tanzania one of few countries in SSA which has supported and provided funding for this service out of the country. However, these services are currently offered in the country with strong collaborations with international institutions. Regulated travel for transplantation as well as provision of local services played a significant role in curbing transplant tourism which has been reported widely in SSA region, contributing to serious medical and psychosocial problems [33-35]. Access to transplantation services which was limited with travel for transplantation in Tanzania is expected to improve with scaling up of local transplantation program.

The local transplantation program at two hospitals in Tanzania will improve access to these services to many needy patients. There is still a lot of work which needs to be done and this includes legal support systems for organ donation as currently there is no legislature governing provision of these services. Transplantation services in Tanzania are provided with observation of Istanbul declaration on organ trafficking and transplant tourism and using special guidelines in the Muhimbili National Hospital establishment act [36].

In order to sustain and build on all these important achievement the NESOT needs to work closely with the government and all other stakeholders to promote enrolment of more nephrology trainees, speed up the establishment of renal nursing training, and improve access by encouraging establishment of dialysis units in all regions. NESOT should also promote and support establishment of peritoneal dialysis and growth of kidney transplantation program. There should be an emphasis on continuous education to improve their 
Table 3 International collaborations for supporting nephrology in Tanzania

\begin{tabular}{ll}
\hline Recipient institutions in Tanzania & Supporting institutions \\
\hline Muhimbili National Hospital (MNH) & Haukeland University Hospital/ \\
University of Bergen, Norway & \\
& \\
& \\
& Madras Medical Mission \\
& BLK Hospital, New Delhi \\
& \\
& \\
Sakra Hospital, Bangalore-India \\
Saifee Hospital, Mumbai-India \\
University of Bergen/ Haukeland \\
University Hospital \\
Christian Medical College- Vellore, \\
Tamil Nadu India
\end{tabular}

Kilimanjaro Christian Medical Centre (KCMC)

Mbeya Referral Hospital

University of Dodoma (UDOM)

Benjamin Mkapa Hospital

Mnazi Mmoja Hospital, Zanzibar
African Paediatric Fellowship Program (APFP), Cape Town, South Africa

Queen's University, Ontario - Canada

International Society of Nephrology

International Society of Peritoneal Dialysis (ISPD)

Manchester Royal Infirmary

Madaktari Afrika, Virginia, USA

Tokushukai Medical Hospital (Tokuda Foundation)/Tokyo Women Medical University, Japan

Tokushukai Medical Group, Japan

University of Bergen/ Haukeland University Hospital, Norway

\section{Support provided}

Donation of 15 dialysis machines

Training of dialysis technicians and histopathology technician

Donation of one GE Logic 7 Ultrasound

Machine (GE Logic 7), 2 Spring Loaded

Magnum Bard Biopsy Guns and several

kidney biopsy needles

Conducted ultrasound guided renal biopsy training

Donation of dialysis machine for ICU

Provided short time training for transplantation to urologists, nephrologist, nurses, anaesthesiologist, laboratory technicians, histotechnicians

Supported kidney transplantation at $\mathrm{MNH}$

Visiting transplant surgeons to support local kidney transplantation

Visiting transplant surgeons to support local kidney transplantation

Training of nephrologists and supported establishment of nephrology training in Tanzania

Training of first batch of nephrologists and supported establishment of nephrology training in Tanzania

Providing on-going external rotation training centre for MUHAS nephrology training

Supported paediatric nephrology training

ISN Sister Centre Program

Provided visiting nephrologist, visiting dialysis nurses and funds for educational activities

Training support for nephrologists

Provided visiting nephrologists and training for the initiation of peritoneal dialysis

The Transplantation Society-ISN sister transplant centre

Vascular access training camps

Provided visiting nephrologist who provided training and support in establishing nephrology services

Donation of 10 dialysis machines and dialysis training for doctors and nurses

Training on kidney transplantation for doctors, nurses, pharmacists, immunologists and technicians

Training on kidney transplantation for doctors, nurses, pharmacists, immunologists and technicians

Supported kidney transplantation of four patients Donation of dialysis machines

Dialysis training for nurses and doctors

Visiting dialysis nurse providing training and support for nurses and doctors 
Table 3 International collaborations for supporting nephrology in Tanzania (Continued)

\begin{tabular}{lll}
\hline Recipient institutions in Tanzania & Supporting institutions & Support provided \\
\hline & & Nephrology Tripartite workshops in \\
& & collaboration with MNH and Haukeland \\
Nephrology Society of Tanzania (NESOT) & International Society of Nephrology (ISN) & $\begin{array}{l}\text { University Hospital } \\
\text { ISN Fellowship training for nephrologists } \\
\text { and pathologist }\end{array}$
\end{tabular}

skills including nutrition especially for CKD patients [37], prevention and early identification of patients with kidney diseases.

NESOT should also promote collaboration with the government of Tanzania and other stakeholders to prepare laws and policies to provide legal framework for supporting kidney transplantation and other services. These policies should also guide all stakeholders to increase focus on prevention of kidney diseases focusing on modifiable risk factors and outreach renal services.

\section{Conclusion}

There has been significant improvement of nephrology services in Tanzania with establishment of local nephrology training programs and kidney transplantation services. The long-standing international collaboration and support have been instrumental in these developments and milestones. These collaborative efforts and achievements should be used as good model for supporting nephrology services in other low-income countries, especially in the African region. To meet the increased need of treating patients with ESKD it is of paramount importance to reduce the costs of dialysis. ISN, IPNA and International Society of Peritoneal Dialysis (ISPD) should continue their efforts in capacity building for nephrology care by continuing to establish programs to support nephrology training in countries with similar resource limitations as Tanzania. National nephrology societies play important role in establishing and strengthening nephrology services through advocacy, linkage between governments and international professional societies like ISN, IPNA and ISPD. Therefore, there should be efforts to support creating of these societies in lower and middle-income countries.

\footnotetext{
Abbreviations

AKI: Acute Kidney Injury; ANIO: American Nephrologists of Indian Origin; BMH: Benjamin Mkapa Hospital; CMC: Christian Medical College; CNC: Clinical Nephropathology Certificate; eGFR: estimated Glomerular Filtration Rate; ESKD: End Stage Kidney Disease; HIV: Human Immunodeficiency Virus; IPNA: International Paediatric Nephrology Association; ISN: International Society of Nephrology; ISPD: International Society of Peritoneal Dialysis; KCMC: Kilimanjaro Christian Medical Centre; LMIC: Lower- and MiddleIncome Countries; MNH: Muhimbili National Hospital; MUHAS: Muhimbili University of Health and Allied Sciences; NCD: Non-Communicable Disease; NESOT: Nephrology Society of Tanzania; NHIF: National Health Insurance Fund; SSA: Sub Saharan Africa; SYL: Saving Young Lives; UCT: University of Cape Town; UiB: University of Bergen; USD: United State Dollar
}

\section{Acknowledgements}

We acknowledge training support, which was offered to FF (ISN, IPNA, and APFP) and KK (ISN and Sustainable Kidney Care Foundation and IPNA).

\section{Authors' contributions}

FF and JS conceptualized the analysis; FF, KK, PR and OK collected data for this analysis; FF wrote the manuscript; GB, KY, SV and ES provided critical appraisal of the manuscript. All authors read and approved the final draft of manuscript.

\section{Funding}

No funding was obtained for this work.

\section{Availability of data and materials}

The datasets used for this work can be requested from the corresponding author on reasonable request.

\section{Ethics approval and consent to participate}

This study was approved by MUHAS Institution Board with waiver of consent was also granted.

\section{Consent for publication}

Not applicable.

\section{Competing interests}

The authors declare that they have no competing interests.

\section{Author details}

'School of Medicine, Muhimbili University of Health Sciences (MUHAS), P. O. Box 65001, Dar es Salaam, Tanzania. ${ }^{2}$ Renal Unit, Muhimbili National Hospital (MNH), Dar es Salaam, Tanzania. ${ }^{3}$ Department of Internal Medicine, Kilimanjaro Christian Medical Centre (KCMC), Moshi, Tanzania. ${ }^{4}$ Department of Renal Medicine, The Alfred Hospital, Melbourne, Australia. ${ }^{5}$ Previously Department of Nephrology, Christian Medical College, Vellore, Tamil Nadu, India. 'Department of Medicine, Division of Nephrology, Queen's University, Kingston, Ontario, Canada. 'Department of Nephrology, Christian Medical College-Vellore, Vellore, Tamil Nadu, India. ${ }^{8}$ Department of Medicine, Haukeland University Hospital and Department of Clinical Medicine, University of Bergen, Bergen, Norway.

Received: 28 February 2019 Accepted: 27 September 2019

Published online: 17 October 2019

\section{References}

1. Naghavi M, Abajobir AA, Abbafati C, et al. Global, regional and national age-sex specific mortality for 264 causes of death, 1980-2016: a systematic analysis for the global burden of disease study 2016. Lancet. 2017;390:1151-210.

2. Mathers $C D$, Loncar D. Projections of global mortality and burden of disease from 2002 to 2030. PLoS Med. 2006;3(11):e442. https://doi.org/10.1371/ journal.pmed.0030442.

3. Mayige M, Kagaruki G, Ramaiya K, Swai A. Non communicable diseases in Tanzania: a call for urgent action. Tanzania J Heal Res. 2012;14:2.

4. Jager KJ, Fraser SDS. The ascending rank of chronic kidney disease in the global burden of disease study. Nephrol Dial Transplant. 2017;32:ii121-8. https://doi.org/10.1093/ndt/gfw330.

5. Naicker S. Challenges for nephrology practice in sub-Saharan Africa. Nephrol Dial Transplant. 2010;25:649-50. https://doi.org/10.1093/ndt/gfp727.

6. Naicker S. End-stage renal disease in sub-Saharan and South Africa. Kidney Int. 2003;63(83):S119-22. 
7. Harris DCH, Dupuis S, Couser WG, et al. Training nephrologists from developing countries: does it have a positive impact? Kidney Int Suppl. 2012;2:275-8.

8. Brown FG. Empowerment of young nephrologists in developing countries: the role of the ISN young nephrologists committee. Kidney Int Suppl. 2013; 3:184-5.

9. Naicker S. End-stage renal disease in sub-Saharan Africa. Kidney Int Suppl. 2013;3:161-3. https://doi.org/10.1038/kisup.2013.4.

10. Ramaiya K. Setting up diabetes clinics in Tanzania. Pract Diab Int. 2006;23(8): 339-40.

11. Stanifer JW, Maro V, Egger J, Karia F, Thielman N, Turner EL, et al. The epidemiology of chronic kidney disease in northern Tanzania: a populationbased survey. PLoS One. 2015;10(4):e0124506. https://doi.org/10.1371/ journal.pone.0124506.

12. Ploth DW, Mbwambo JK, Fonner VA, Horowitz B, Zager P, Schrader R, Fredrick F, Laggis C, Sweat MD. Prevalence of CKD, diabetes, and hypertension in rural Tanzania. Kidney Int Rep. 2018;3:905-15. https://doi. org/10.1016/j.ekir.2018.04.006

13. Janmohamed, et al. Prevalence of chronic kidney disease in diabetic adult out-patients in Tanzania. BMC Nephrology. 2013;14:183.

14. Kilonzo SB, Seiffudin AT, Bakshi FA, Gunda DW. Renal dysfunction among adult patients in Mwanza, Tanzania: prevalence, outcomes and associated factors. Tanzan J Health Res. 2016;18:3. https://doi.org/10.4314/thrb.v18i3.5.

15. Sylvanus E, Sawe HR, Muhanuzi B, Mulesi E, Mfinanga JA, Weber EJ, Kilindimo S. Profile and outcome of patients with emergency complications of renal failure presenting to an urban emergency department of a tertiary hospital in Tanzania. BMC Emergency Med. 2019;19:11.

16. Msango L, Downs JA, Kalluvya SE, Kidenya BR, Kabangila R, Johnson WD Jr, Fitzgerald DW, Peck RN. Renal Dysfunction among HIV-Infected Patients Starting Antiretroviral Therapy in Mwanza, Tanzania. AIDS. 2011;25(11):14215. https://doi.org/10.1097/QAD.0b013e328348a4b1.

17. Kayange NM, Smart LR, Downs JA, Maskini M, Fitzgerald DW, Peck RN. The influence of HIV and Schistosomiasis on renal function: a cross-sectional study among children at a Hospital in Tanzania. PLoS Negl Trop Dis. 2015; 9(1):e0003472. https://doi.org/10.1371/journal.pntd.0003472.

18. Fredrick F, Francis JM, Ruggajo PJ, Maro EE. Renal abnormalities among HIV infected children at Muhimbili National Hospital (MNH)—Dar Es Salaam, Tanzania. BMC Nephrol. 2016:17:30. https://doi.org/10.1186/s12882-0160242-6.

19. Fredrick F, Ruggajo PJ, Makanga G, Shija CK, Amdemariam M Rugwizagonga B, Kitinya JN. Thirty years old lady with nephrotic syndrome: a case of biopsy proven lupus nephritis in Tanzania. Tanzan J Health Res. 2014;16(2):127-30

20. Meremo AJ, Ngilangwa DP, Mwashambwa MY, Masalu MB, Kapinga J, Tagalile R, Sabi I. Challenges and outcomes of haemodialysis among patients presenting with kidney diseases in Dodoma, Tanzania. BMC Nephrol. 2017;18:212. https://doi.org/10.1186/s12882-017-0634-2.

21. Kilonzo KG, Ghosh S, Temu SA, Maro V, Callegari J, Carter M, Handelman G, Finkelstein FO, Levin N, Yeates K. Outcome of acute peritoneal dialysis in northern Tanzania. Perit Dial Int. 2012;32:261-6. https://doi.org/10.3747/pdi. 2012.00083.

22. Kilonzo K, Mathew A, Croome AJ. Establishment of an acute peritoneal dialysis program in Tanzania. Kidney Int Suppl. 2013;3:186-9. https://doi.org/ 10.1038/kisup.2013.11.

23. Smoyer WE, Finkelstein FO, McCulloch Ml, Carter M, Brusselmans A, Feehally J. "Saving young lives" with acute kidney injury: the challenge of acute dialysis in low-resource settings. Kidney Int. 2016;89:254-6 https://doi.org/10 1016/j.kint.2015.10.009

24. Fredrick F, Valentine G. Improvised peritoneal dialysis in an 18-month-old child with severe acute malnutrition (kwashiorkor) and acute kidney injury: a case report. J Med Case Rep. 2013;7:168. http://www.jmedicalcasereports. com/content/7/1/168.

25. Basinda SL, Maro EE, McLarty DG, Young AE, Wing AJ. Ten Tanzanian transplants: problems and perspectives. Postgrad Med J. 1988:64(756):778-82.

26. Fredrick FF, Ruggajo PJ, Basu G, Svarstad E, Langeland N. Global collaboration bears fruit: Tanzania report. Kidney Int. 2015:88:1211-4. https:// doi.org/10.1038/ki.2015.248

27. Bijol V, Farag YMK, Shah S, Feehally J, Singh AK. The International Society of Nephrology (ISN) and the American nephrologists of Indian origin (ANIO) online clinical Nephropathology certificate (CNC) program. Kidney Int. 2016; 89:966-8. https://doi.org/10.1016/j.kint.2015.11.035.
28. Janmohamed M, Fredrick F, Bhandari S. Nephrology in developing and developed nations: worlds apart but many similarities. Br J Renal Med. 2018; 23(4):92-6.

29. Pancras G, Shayo J, Anaeli A. Non-medical facilitators and barriers towards accessing haemodialysis services: an exploration of ethical challenges. BMC Nephrol. 2018;19:342.

30. Mushi L, Krohn M, Flessa S. Cost of dialysis in Tanzania: evidence from the provider's perspective. Health Econ Rev. 2015;5(1):28. https://doi.org/10. 1186/s13561-015-0064-4. Epub 2015 Oct 13.

31. Amu H, Dickson KS, Kumi-Kyereme A, Darteh EKM. Understanding variations in health insurance coverage in Ghana, Kenya, Nigeria, and Tanzania: evidence from demographic and health surveys. PLoS One. 2018;13(8): e0201833. https://doi.org/10.1371/journal.pone.0201833.

32. Raimann GJ, Riella MC, Levin NW. International society of Nephrology's Oby25 initiative (zero preventable deaths from acute kidney injury by 2025): focus on diagnosis of acute kidney injury in low-income countries. Clin Kidney J. 2018;11(1):12-9.

33. Ambagtsheer F, Zaitch D, Swaaningen R, Duijst W, Zuidema W, Weimar W. Cross-Border Quest: The Reality and Legality of Transplant Tourism. J Transplant. 2012;2012:7. https://doi.org/10.1155/2012/391936.

34. Amira CO, Bello BT. Do the benefits of transplant tourism amongst Nigerian patients outweigh the risks? A single-center experience. Int J Org Transplant Med. 2017;8(3):132-9.

35. Okafor UH. Transplant tourism among kidney transplant patients in eastern Nigeria. BMC Nephrol. 2017;18:215.

36. International Summit on Transplant Tourism and Organ Trafficking Convened by The Transplantation Society and International Society of Nephrology in Istanbul, Turkey, April 30 through May 2, 2008: The Declaration of Istanbul on Organ Trafficking and Transplant Tourism. CJASN. 2008;3(5):1227-31. https://doi.org/10.2215/CJN.03320708.

37. Munuo AE, Mugendi BW, Kisanga OA, Otieno GO. Nutrition knowledge, attitudes and practices among healthcare workers in management of chronic kidney diseases in selected hospitals in Dar Es Salaam, Tanzania; a cross-sectional study. BMC Nutrition. 2016;2:6. https://doi.org/10.1186/ s40795-016-0045-y.

\section{Publisher's Note}

Springer Nature remains neutral with regard to jurisdictional claims in published maps and institutional affiliations.

Ready to submit your research? Choose BMC and benefit from:

- fast, convenient online submission

- thorough peer review by experienced researchers in your field

- rapid publication on acceptance

- support for research data, including large and complex data types

- gold Open Access which fosters wider collaboration and increased citations

- maximum visibility for your research: over $100 \mathrm{M}$ website views per year

At BMC, research is always in progress.

Learn more biomedcentral.com/submissions 